\title{
Is Government Welfare Able to Change? Analysing Efforts to Co-create an Improved Social Welfare System through Taking Advantage of a Collaborative Economy
}

\author{
Gerli Aavik, Anna Mayer, Keegan McBride, Robert Krimmer \\ Tallinn University of Technology, Tallinn, Estonia \\ \{Gerli.Aavik | Anna.Mayer | Keegan.McBride | Robert.Krimmer@taltech.ee\}
}

\begin{abstract}
Welfare sectors across the world are facing the need to balance the contrast between economic pressures due to demographic changes and peoples' rising expectations of receiving services that are transparent; timely and tailored to citizens' habits and needs. This means that governments are pressured to look for new ways to deliver public services. This article looks at two cocreated peer-to-peer platforms that are engaged in delivering public services in the welfare sector, Helpific and Caremate, and their development and role in the Estonian welfare sector. These platforms appear to hold substantial potential for changing the current system of delivering public services, however they have not yet managed to acquire the anticipated level of success. By examining these two cases, it is proposed that the room and support for developing new solutions, using experience in the field and overcoming the digital divide must be assured in order to make changes in government welfare possible.
\end{abstract}

\section{Introduction}

In the current age of AirBnB, Uber, and Amazon, society's expectations for services are rapidly changing due to the influence of new technologies. Citizens expect government to be transparent, public services to be fast and effective, in-tune with their wants and needs, and there is now an increased effort to 'co-create', or involve many stakeholders in the design, delivery, and implementation of new public services [1]. Many governments are starting to acknowledge that demographics are changing, populations are aging, and there is increased economic pressure on governments to deliver services in an optimized fashion [2]. Governments are now experimenting with co-creating new public services in order to become more innovative, cost effective, and engaged with their citizens [3].

Additionally, today's society is becoming increasingly digitalized and governments are beginning to open up access to their data, whilst hoping that open data will lead to added public value and newly cocreated public services [4]. Citizens can use open government data to see whether the government is actually delivering services to them in a way that they feel is fair and are beginning to demand more usercentered services that are easy and efficient to use [5]. However, there is a clash between citizens' expectations of services government provided and the current reality for services. Thus, we must understand how welfare service providers can begin to empower rather than inhibit users of their services.

Collaborative approaches, such as co-creation and the peer-to-peer economy are one way of overcoming the 'one-size-fits-all' solutions public administrations are so accustomed to, and of customizing services in a more innovative way [6]. These collaborative practices can give citizens a voice concerning issues that are most important to them, for example welfare policies [7] and it can also be an opportunity to increase the public sector's legitimacy and to access society's resources [8;9]. Collaborative approaches allow a wide variety of experiences and expertise to be brought together and thus these can provide a platform for presenting many new ideas [10]; this may lead to services that are more efficient and more in-tune with user's needs while also allowing the service provider to ask questions and understand other perspectives [6]. Co-creation also appears capable of strengthening social cohesion in the context of a highly fragmented society [8], of benefiting from innovations in the tertiary and in the private sector [9], of helping bureaucracies overcome the thinking in departmental silos [2], of creating synergy between what governments do and what citizens do [11] and of strengthening local democracy [12]. Although cocreation appears to be beneficial, it should not be taken for granted and there must be a debate about when and where co-creation is acceptable and likely to provide a better outcome than other alternatives; this is not a onesize-fits all solution.

It seems to be the case that a collaborative, peer-topeer and co-creation based approach for delivering public services in the welfare sector may provide benefits for users of the services and those responsible 
for delivering welfare services. However, there is only limited empirical work on the use of the peer-to-peer economy and co-creation combined for delivering public services. This paper aims to address this current lack of empirical work by conducting a multiple case study of two different peer-to-peer platforms, Helpific and Caremate, which are committed to the co-creation of public services in the Estonian social welfare system and by addressing the following research questions:

- Why have Helpific and Caremate not been more successful, despite the potential they seem to hold?

- What role can a co-created peer-to-peer economy based platform play in delivering public services?

- What are the factors influencing the development and implementation of public services based on a co-created peer-to-peer platform?

Both services being studied as part of this case study function in the social welfare sector, provide support for people who need it due to some sort of inhibiting factor, and both have emerged from work done by groups of citizens at government-initiated hackathon ideas events. These services have received notable public attention, including activating discussions on whether some of the government resources dedicated to offering similar services should be directed towards such peer-to-peer platforms. However, the development of these solutions has not been as rapid as many of the stakeholders anticipated. This exploratory paper can provide initial insights into this emerging topic.

\section{Framework}

The content, context and process (CCP) framework is used in order to understand links between content, context and process and to properly structure and analyzed data. The CCP framework allows breaking processes into different elements - purpose (why), subject (what), timeframe (when), methodologies (how) and people (who) [13]. In the current article, the CCP framework enables us to structure the case by looking at the content that is being changed (delivery of social welfare services in Estonia), the content of the change (operating on co-created peer-to-peer platforms, such as Helpific and Caremate), the context surrounding the change (sustainability of the social welfare system, the current organization of the social welfare system, including the main stakeholders in play, and the overall context of innovation in Estonia) and the process of change (focusing on how content changes, how these changes are communicated and whether the timing was right for the change).
The underlying assumption for this paper is that most organizations cannot be changed easily and elements of path-dependency tend to emerge when transformative changes are attempted [14]. Pathdependency theories must be viewed critically, since continuity and change occur simultaneously in real life situations [15]. Still, they can help us understand why transformative changes in organisations, especially in the public sector are scarce. The principal arguments used in this paper are that changes are most likely to be accepted when the core values of organizations are not impacted [16], when there are little or no substantial mismatches between contextual dimensions [17], when acceptance is gained amongst stakeholders, when there is thorough communication [18] and when the timing is right [19]. Another assumption is that when the content of change is co-created, it is more likely to be compatible with expectations of stakeholders involved and to be successful. For the purpose of this paper, public services are understood to be any service that is provided by any stakeholder if it adds public value [20]. Public value is seen as public good, which in this case is regarded as help provided to those in need. The paper will examine whether using the elements of co-creation and peer-to-peer platforms will help overcome the resistance to change prevalent in the public sector. Following the CCP framework, the principal arguments are tested and developed further and the research questions answered.

\section{Methodology}

A qualitative research approach is followed for this paper; research designed on this matter allows for links between causally relevant factors to be analyzed in the light of the theoretical framework chosen [21]. When analysing contemporary phenomena, in-vivo case studies are often viewed as an appropriate methodology, as they allow researchers to understand the dynamics within a specific context [22]. Case studies are often criticized for their external validity, but in situations where there is little previous empirical work, they can provide new beneficial insights [23]. This paper aims to follow a multiple case study research approach to help improve external validity by studying two different examples of peer-to-peer platforms in Estonia: Helpific and Caremate. Since there are only limited examples of such co-created peer-to-peer platforms in the social welfare sector and even those limited examples are relatively new, the explorative approach is chosen to examine any possible causal relationships and consider contextual factors surrounding these developments. To make conclusions applicable to other contexts, all the findings must be validated in the next phases of research by including other examples from different contexts. 
13 semi-structured interviews were carried out with 14 local experts, in order to understand the factors in play here properly. Interviews lasted from 30 to 90 minutes and were carried out either in person (11 interviews), via Skype (one interview) or on the telephone (one interview). All interviews were transcribed, translated into English, analysed and coded. The interviewees included stakeholders from the following organizations: Estonian Ministry of Social Affairs (EMSA), Estonian Ministry of Economic Affairs and Communication, the Government Office of Estonia, Estonian Parliament, local municipalities in Estonia, Estonian Sharing Economy Alliance, Estonian Chamber of Disabled People, representatives of Estonian civil society and social service providers, and members of both Helpific and Caremate. The viewpoints provided by these stakeholders, together with documentary analysis, allowed deeper insights to be gained into how peer-to-peer solutions could be used to assist in the delivery of public services. Additionally, the interviews shed light on how the Estonian public sector interacts and how it views the Estonian social welfare sector and how local communities and civil society seek new ways to play a role in the process of creating public services.

\section{The Case of Estonia}

Two peer-to-peer web-based platforms offering public services in the welfare sector form the scope of this article. This section provides a short overview of the Estonian welfare sector and current delivery of services, the concepts of Helpific and Caremate are explained, the context surrounding attempts to transform the delivery of social services and the process of initiating the two platforms in focus here is explained.

\subsection{Current delivery of welfare services in Estonia and attempts to transform the sector}

The provision of traditional social services in Estonia is divided between central government and local municipalities - central government being responsible for special care and social rehabilitation services and technical aid, and local municipalities for all other social services, including services mediated through Helpific and Caremate, such as social transportation, domestic services and personal support services. It is important to note that even though the local municipalities must organise the services, they are also permitted to charge fees for them (the financial situation of the person receiving the service and his or her family must be taken into consideration) [24]. This means that peer-to-peer platforms offering social services at a community level in Estonia have two potential target groups who could finance their activities - people who need the support (including their families) and who organize the services and pay for these themselves and the local municipalities who struggle finding service providers to fulfil their obligation to help people in need who must rely on municipalities.

The Estonian social welfare sector currently faces many difficulties. According to the World Bank report [25], the Estonian population is ageing rapidly, is less healthy than the EU average and requires more assistance with activities of daily living. The Shadow Report on fulfilling the Convention on the Rights of Persons with Disabilities in Estonia [26] states that the availability of support services for people with disabilities is inadequate and is highly dependent on the municipality where the person in need lives. This very fact was confirmed by several interviewees. The current state of the Estonian social welfare sector was discussed with 10 people interviewed. Most interviewees thought that the current organization of the sector is not sustainable and that significant changes are required. The principal critical aspects highlighted were the lack of flexibility in service provision, lack of resources (both monetary and in terms of support persons), the slow speed in developing new solutions and the poor reputation of the sector. A few people also mentioned that Estonia has tried to copy welfare models that have already proven not to be sustainable and that the state should strive to develop new models, not copy other models. Several interviewees mentioned that efforts must be made to attract private stakeholders to the sector and better use must be made of volunteers and to involve communities. In different engagement events for the users of services, the target group representatives also highlighted that the current organisation of services is too rigid and does not match the actual needs of the people. Co-creating new solutions together with users of the potential services could help overcome some of these issues.

The use of a peer-to-peer economy in welfare sector has been regarded as one solution for addressing some of these issues. Two such examples, Helpific and Caremate, are examined in this paper. The basic idea behind Helpific was the fact that a professional care provider is not needed to help someone complete their shopping or to accompany a person with a disability to a concert - community resources could be used for this. With Caremate, the focus was on creating flexibility for both professional care providers and for the people who need care - for example, instead of care providers spending one third of the day driving from one client to another, they could choose clients nearby and could reach more people. While Helpific focuses mainly on working with volunteers found in communities and 
paid-for services make up a smaller proportion of the platform, Caremate focuses exclusively on mediating professional paid-for services. Another important difference is that the Caremate platform includes training courses for care providers. Previous training (either professional training or courses and exams taken through the platform) is a prerequisite to offering any services through the Caremate platform. These courses can also be used separately, for example when unofficial informal caregivers (usually family members) want to extend their knowledge on the correct methods of providing care. While these solutions are private initiatives and currently have no government participation, both solutions arose from governmentinitiated hackathons and both platforms concentrate on services usually organized by local municipalities. Therefore, we regard the solutions as alternative routes for providing public services. The main similarities and differences between the two platforms are highlighted in Table 1. A more detailed overview on how these platforms were initiated and developed is given in section 4.3.

Table 1. Similarities and differences between Helpific and Caremate.

\begin{tabular}{|l|c|c|}
\hline Platform Characteristics & Helpific & Caremate \\
\hline $\begin{array}{l}\text { Connects volunteers to } \\
\text { those who need help }\end{array}$ & $\mathrm{X}$ & \\
\hline $\begin{array}{l}\text { Connects paid workers to } \\
\text { those who need help }\end{array}$ & $\mathrm{X}$ & $\mathrm{X}$ \\
\hline $\begin{array}{l}\text { Requires platform users to } \\
\text { have previous training }\end{array}$ & $\mathrm{X}$ \\
\hline $\begin{array}{l}\text { Offers training needed to } \\
\text { provide care }\end{array}$ & $\mathrm{X}$ \\
\hline $\begin{array}{l}\text { Services are directed } \\
\text { towards people with special } \\
\text { needs simpler }\end{array}$ & $\mathrm{X}$ & $\mathrm{X}$ \\
\hline $\begin{array}{l}\text { Focuses on susces, such as providing } \\
\text { services, } \\
\text { transportation, help with } \\
\text { household tasks or acting as } \\
\text { a personal assistant) }\end{array}$ & $\mathrm{X}$ \\
\hline $\begin{array}{l}\text { Focuses on care services } \\
\text { (including services that need } \\
\text { special training) }\end{array}$ & $\mathrm{X}$ \\
\hline $\begin{array}{l}\text { Operates on a peer-to-peer } \\
\text { platform }\end{array}$ & $\mathrm{X}$ & $\mathrm{X}$ \\
\hline $\begin{array}{l}\text { Are co-created together with } \\
\text { potential service users }\end{array}$ & $\mathrm{X}$ & $\mathrm{X}$ \\
\hline
\end{tabular}

It is important to note that while both platforms have received relatively high public attention and are often referred to as having potential to transform the traditional delivery of public services, they have not yet managed to achieve the anticipated level of success. By the time of interviews, 4500 people had registered to use the Helpific platform and around 250 people had received help through it. However, there are around 150,000 people with disabilities in Estonia, meaning that the number of people using the platform is a fraction of potential user numbers. By the time of conducting the interviews, Caremate had not yet opened the platform to the public and this was still in the test phase, however they had already started negotiations with possible public sector partners, such as local municipalities.

\subsection{The Estonian context and specifics of the welfare sector}

Estonia brands itself as the "trailblazer" and the place where things happen first. It has also gained a reputation for being a start-up country. Estonia ranks third in Europe concerning the number of start-ups per capita, behind Iceland and Ireland, which is often explained by the fact that registering new enterprises in Estonia is relatively easy and there is no corporate income tax on undistributed (retained) profits [27]. Another consideration is that for a small state, Estonia has created a remarkable image of an e-state - the country offers wide usage of e-services, charismatic leaders in the field of e-governance and a drive to achieve new levels of efficiency [28]. Still, the interviews carried out showed that Estonia is not always as open to new ideas as its external image shows and that most of the success stories evolve around digitalizing public services, meaning that the principles of how services operate often remain unchanged.

A good example here is the process of legalising transportation platforms like Uber. Estonia was set to become the first country in Europe to legalise Uber and it started off with an ambitious draft where a separate category, distinct from the public transport category, with more flexible regulations was created for ridesharing. However, during the negotiations, the proposal was changed significantly and the bill ended up regulating the ridesharing service in the same way the taxi service is regulated - meaning that Uber drivers must match the same criteria as taxi drivers. [29] While the requirements for taxi drivers were also relaxed during these negotiations and many stakeholders interviewed regarded this as a good solution, we must report that a rather traditional approach was chosen to regulate a completely new concept of service delivery. As one of the interviewees said "Basically, instead of making the system just as easy for taxi drivers as it was for platform drivers, the opposite occurred and the platform drivers had to start matching up to the standards." Similar paradoxes of the reality not matching the external image were also highlighted in a recent article by Lember et al [30] - they argued that even though the country is seemingly technology- 
friendly, the change in technological capacities is uneven and for the most part is slow.

Interestingly, when discussing the question of whether Estonia is a good place to start new innovative ventures, half the interviewees regard the openness to innovation as hype, while the others were more optimistic and said that Estonia generally is an innovation-friendly country, just not necessarily in all areas of life. Some recurrent topics emerged when looking at the aspects of what makes Estonia a good place for new innovative solutions and what the barriers are. On the positive side, the following aspects were mentioned: the personal nature of relationships helps get things done faster; digitalization of the public sector creates a lot of the prerequisites for developing new solutions; Estonians are generally open-minded; not many legal obstacles are created by the state, a lack of resources in most areas has made Estonians creative and there is a lot of support available for new start-ups. The barriers discussed were mostly as follows: lack of support for innovation from many local municipalities; the belief among decision-makers that they hold all the answers themselves; risk aversion; the size of the market makes it hard to scale-up new solutions; financing mechanisms which hinder innovation; the lack of sharing experiences and the government remaining in its comfort zone. It was also mentioned that even though there are not many legal restrictions, the legal system does also not actively support innovation.

In the context of developing Helpific and Caremate, we must consider that the lack of support for new solutions from local municipalities was identified as one of the main barriers to innovation. As many as nine people identified local municipalities as "the weakest link" in the Estonian system. Since local municipalities play a crucial role in policymaking and implementation, this reflects strongly on the phenomena that Estonia tends to be more innovative in rhetoric than in practice and that the success stories tend to be from centrally digitalizing services.

It is also important to note that the social welfare sector has its own specifics. The most important stakeholders in the Estonian social welfare sector are EMSA together with its agencies (such as the Social Insurance Board), the local municipalities, private service providers and civil society and the service users themselves. These stakeholders must to be included in order to successfully co-create new welfare services. Several interviewees mentioned that the welfare sector has not seen a lot of innovation and even though there have been some positive changes in recent years, the routines for how things are done have for the most part remained the same. We should also consider that due to the vulnerability of the target groups, there tends to be more caution to changing practises. However, the sector has seen remarkable changes in recent years. EMSA has been organizing co-creation workshops to gather new ideas for solving issues in the welfare sector, there have been hackathons dedicated to solving social issues and in 2018 a new measure was launched to support the development of innovative ideas: one million euros is divided between supporting the development of ideas into prototypes and four million euros to support developing and piloting working solutions. A representative from EMSA also reflected that, many lessons were learned while preparing these measures and flexible changes were made. Many stakeholders mentioned that they are hopeful that these measures will finally help bring more innovation in the welfare sector, including solutions co-created with service users.

Another important aspect that must be looked at in the context of developing peer-to-peer solutions like Helpific and Caremate are attitudes towards community involvement in the public sector and the delivery of public services. Estonian president Kersti Kaljulaid has talked about the need to develop tailor-made services and involve civil society. In one of her speeches she discussed, whether a social worker should be able to pay a neighbour to fetch winter wood for elderly, instead of organising costly and complicated services [31]. This speech, along with the rise of peer-to-peer platforms, has accelerated the discussions on using peer-to-peer solutions for providing public services in a more flexible way. One possible solution was proposed by the Expert Group on Self-Driving Vehicles created by the Government Office - the expert group proposed creating the legal possibilities for crowdsourcing public services from the communities, so called folk procurements [32]. As described by a representative of the Government Office, "The basic idea is that there would be an environment for micro procurements where every validated user could offer such services as they can and are qualified for - be it providing social transportation for elderly persons or cleaning roads in some local municipality. Any simple tasks that must be completed on large scales could be procured through that environment." Whilst this proposition has not yet become a reality, it has created some interesting domestic discussions and must be tracked in future research, since it has the potential to bring about transformative changes in the delivery of public services.

Strategic documents, such as the Welfare Development Plan [33] in the social welfare sector also demonstrate that new innovative solutions from the private sector and local communities are expected. However, expecting meaningful collaboration with different stakeholders and actually enforcing collaborative practices are not one and the same thing. The interviews showed that co-creation practises tend to 
be project-based and are often not being integrated into day-to-day processes. Another important factor here is that due to the sensitive nature of social welfare data and the lack of efforts to systematically open up anonymized data, it can be harder for active citizens to build good evidence-based solutions. In a way this keeps the power of information with public organisations and makes it harder for good citizen-initiated solutions to grow into scalable solutions. Several interviewees also highlighted that Estonia tends to be a top-down country and there are shortcomings in including citizens meaningfully. However, most of the interviewees believed that local communities and volunteers must be involved and cocreation practices must be improved.

\subsection{The process of initiating and developing Helpific and Caremate}

Helpific is the first peer-to-peer platform in the Estonian social welfare sector to receive wide attention. The idea was mainly based on looking at peer-to-peer models from other sectors. These observed that a peerto-peer economy had already revolutionized some areas, such as transportation and accommodation, but they noticed that similar examples cannot really be found in the social welfare sector. The initiators believed that in the social welfare sector, using peer-to-peer solutions could revolutionize the field in a similar way. Caremate followed with their idea a few years later.

Both Helpific and Caremate were initiated in hackathons, organised either by EMSA or in cooperation with EMSA. Helpific was initiated in 2014 and Caremate in a hackathon in 2017. The basic idea of these hackathons is that people from different backgrounds (such as designers, developers, the welfare experts, target group representatives etc.) come together and work on ideas pitched by initiators. During these hackathons, teams are supported by mentors and experts working in different fields. In both cases the main initiators had already worked on their ideas beforehand, but they came to the hackathons to form teams and take the next step. The initiator of Helpific ran an organisation, representing women with disabilities and she noticed that current public services do not cover all the support needs people have. The initiator of Caremate had worked as a caregiver and similarly regarded that the current organisation of services needed changing. During the hackathons people from different backgrounds, including potential users of services and people representing government organisations worked together to develop their ideas further. Both initiatives succeeded at their hackathons. Helpific received the Audience's Favourite award, while Caremate won its event, received the Audience's Favourite title and a special prize from Mindtrak.
The teams continued to actively develop their ideas further after the hackathons. Both solutions took part in Ajujaht, the biggest business idea competition in Estonia, and reached the TOP30 - Helpific in the 2015/2016 competition and Caremate in the 2017/2018 competition. Ajujaht provided both solutions support and advice from mentors and potential investors. In addition, Caremate took part in another competition called "Prototon" that provided additional support for developing the idea into a working prototype. Both platforms also managed to get support developing ITplatforms from the crowdsourcing platform Hooandja Helpific collected the money needed in July 2017 and Caremate in April 2018.

It is important to note that both initiatives followed the minimal viable product approach, where first tests with clients were carried out, with analogue solutions and the rapid gathering of feedback. Also, both solutions undertook comprehensive market research whilst developing their solutions. Helpific conducted a questionnaire among potential target group members and potential helpers and identified the peoples' needs (what kind of support they need, how often, how would they like to receive it etc.) and willingness of helpers (what kind of support and how often are they willing to provide it, what is their previous experience etc.). Caremate had three people who at the time were working in the Social Insurance Board and they had the experience and contacts to complete extensive market research. Among other things it was identified that whilst people expect more flexibility from services, they do not often have the resources to buy services on the open market. This means they must rely on help organised by either local municipalities or by the state.

As both platforms identified the link with the public sector and traditional public services, they also reached out to local municipalities to co-operate. In 2016, Helpific connected all 15 counties, but they only managed to fix meetings with two municipalities. In their business plan, Helpific was able to show that the platform could provide twice as much support for the same sum of money as they currently use for services such as personal support services, by combining the resources of voluntary helpers and paid professionals in their municipality. During meetings with the municipalities that they were able to arrange, the interest and initiative from the municipalities was still low. With one of these no cooperation followed, with the other a different form of collaboration was formed within a Horizon2020 project, aiming to increase community involvement and develop a collaborative public sector. This cooperation can potentially lead to co-created public services, but has not yet become an example of a local municipality directing its own resources into a peer-to-peer platform. Caremate had a different 
experience - they also met with representatives of some local municipalities and the feedback has been quite positive. Some municipalities have already expressed an interest to cooperate and there have been negotiations with representatives at a central level to cooperate on using the training platform. The differences might be due to the differences in the organisation of the platform (such as Caremate having higher requirements for the caregivers and so for assuring higher accountability), but several interviewees mentioned that another factor influencing attitudes could be the timing - during recent years, the awareness of such solutions seems to have increased and there is also more support available to develop and test new solutions.

Both teams highlighted the need to have people in the team who understand the customer's needs - in both teams there are welfare experts and people active in this area. For Caremate, it is important to note that the initial team had three members who at the time worked for the Social Insurance Board - meaning they had first-hand access to data concerning the target group of the platform and extensive knowledge on how the social welfare sector works, including what are the strategic aims of the state's stakeholders and what the existing gaps in the system are. One of the interviewees also reflected on this issue stating that whilst people from the private and NGO sectors often have good ideas, the understanding of how government works is required to implement really meaningful changes. With Helpific, their strength was in having target group representatives in the team.

\section{Discussion}

The initial assumption for this paper was that pathdependency tends to emerge when attempts are made at transformative changes. The co-created peer-to-peer platforms Helpific and Caremate were regarded as attempts to challenge the delivery of public services in the Estonian welfare sector. The proposal was that changes are most likely to be accepted when the core values of organizations are not impacted, when there are little or no substantial mismatches between contextual dimensions, when acceptance is gained amongst stakeholders, when there is thorough communication and when the timing is right. It was also argued that cocreating new solutions can help gain acceptance amongst stakeholders and increase the probability of success.

Despite the outward reputation of Estonia being open to change, the existence of path-dependency in the welfare sector appeared to be evident. However, it looks like the Estonian government is increasingly creating room for new solutions to be co-created. When cocreating services, it is essential to assure that government-stakeholders participating in the cocreation process are the ones actually making the decisions. In the two cases under observation, the statelevel stakeholders were included in the process, while local municipalities who are actually responsible for the services these platforms provide alternatives for, were not included in these first steps. This means that in addition to the question of the openness of local municipalities, the compatibility of new solutions with the needs of local municipalities may be questioned. The initial interviews with local level representatives showed that concerns such as issues relating to public financing, legality, accountability, and security emerged and that these factors must be examined further. Assurance must also be given that the business model is sustainable. For example, one representative at the local municipality level mentioned with regard to Caremate, that the platform services are currently not able to compete with the cheap prices local municipalities are able to arrange themselves. However, the same interviewee said that despite higher prices, they might be willing to cooperate in future due to workforce shortages. Also, the interviewee could see the value in adding coordinated volunteers to the mix of service provision (in the example of Helpific), so that we should question whether communication with local municipalities was adequate during the negotiations.

For both cases studied, the issue of acceptance amongst stakeholder groups appeared to be the single most critical part. While both cases received attention from the public and are regarded as solutions that make a positive impact, cooperation with stakeholders that can ensure the sustainability and integration of the services into day-to-day operations has not yet been achieved. As previously mentioned, the potential target groups are those in need who currently fund and arrange services themselves, and local municipalities. In this article, the main focus was on looking at the local municipalities as the most likely partner. The initial assumption here was that due to the digital divide amongst the target group, the platforms are most likely to reach the direct service users in cases where they are mediated by local municipality social workers who coordinate the rest of the support for the people. Also, it was assumed (based on different surveys carried out amongst target groups) that people needing high levels of support do not often have the resources required to pay for the services themselves, and so they must rely on what the local municipality or the state provides. When examining possible reasons why the service users do not use the platforms directly, these assumptions were confirmed - the feedback from experts in this field and target group representative organisation showed that the main issues are a general lack of awareness, lack of technological know-how, and lack of financial 
resources. Several interviewees proposed that the lack of awareness and the technological limitations could be overcome by using contact points already working within the system to disseminate knowledge of the new services. For example, using local municipality social workers as intermediaries or 'middle-men' helping people use these platforms. Financial aspects could be solved when some of the public money intended for services of a similar nature could be directed to these platforms. The prerequisite here is that these platforms are able to create added value for these municipalities, including operating existing resources more efficiently or increasing the satisfaction levels of service users. It is also important to understand that within these vulnerable target groups, innovations cannot rely merely on digital tools. The capabilities of possible service users must be taken into account. We can assume that those currently using the Helpific platform are the people possessing more advanced levels of digital skills. The influence of timing also seemed to have an impact. This is demonstrated by the difference in feedback amongst local municipalities. Whilst the platforms also provide different possible merits to municipalities, it looks as if Caremate was more readily accepted due to changes in context (such as opening innovation measures by EMSA) and so with better timing. We must note however that as the Caremate platform is not yet open to service users (it is still in the testing phase) it is too early to judge how the potential service users will receive that platform.

It does appear to be the case that co-created peer-topeer based solutions are likely to be compatible with contexts they are introduced into, and thus likely to gain acceptance. The prerequisite here is that all relevant stakeholders are included in the co-creation process. Though collaborative and open approaches to public service creation may be criticized, bringing together different stakeholders does allow the creation of new services that are more in-tune with users' needs. Cocreation can help address criticisms and inefficiencies of traditional public services, by involving both service users and government stakeholders in a meaningful way. However, we should note that such processes may not be suitable for all services and the question of "when are co-created peer-to-peer services more likely to benefit the service user as against the traditional approach' must be explored further. Whilst several people interviewed stated that most public services could possibly be provided by peer-to-peer platforms like Helpific and Caremare, many others also believed that the state should be in control of service delivery and these peer-to-peer solutions should be viewed only as supplementary organizations.

Reflecting back to the first research question of why have Helpific and Caremate not been more successful, there appear to be several issues in play. First, it appears that in the welfare sector the support for new solutions has not been as strong as in other fields, meaning that the sector has behaved more in a path-dependent manner than as a path-creator. Also, there appears to be several barriers in play, hindering changes in the welfare sector. When regarding service users, the main barriers seem to be the lack of awareness, lack of resources and the digital divide. Close cooperation with those currently responsible for organizing traditional public services is needed, in order to overcome these barriers. In the cases under consideration, the most likely counterparts for this cooperation would be local municipalities who however were not participants in the co-creation of these solutions. One the one hand, local municipalities were identified by the interviewees as the stakeholders least open to innovation. At the same time that local municipalities were not part of the co-creation process, compatibility was not assured within that process and issues such as trust, accountability and security have not yet been addressed and resolved. To overcome some or all of these issues, the compatibility of these new service platforms and the needs and values of local municipalities must be met. Overcoming the barriers relating to local municipalities may mean that local municipality social workers could be used as mediators for these platforms and some of the resources dedicated to 'traditional' welfare service delivery could potentially be directed to these platforms, which in turn would help overcome the barriers relating to service users. Further research is needed to fully understand what local municipalities need and value.

With regard to the second research question, asking what role a co-created peer-to-peer economy based platform can play in delivering public services, it looks as if co-created peer-to-peer platforms such as Helpific and Caremate hold the potential to offer alternatives to more traditional public services. Services that are cocreated and function in a peer-to-peer manner may also create higher levels of public value than traditionally delivered services due to the direct involvement of stakeholders in their design and implementation. This approach to public service delivery is both new and innovative, however, it is not a one-size-fits all solution and issues such as trust, accountability, and security must be fully understood before moving forwards. Whilst some interviewees thought that such solutions have the potential to transform traditional public service delivery, others believed that they should be viewed rather as complementary services to public services provided traditionally. Regardless of which opinion is adopted, these services, if accepted by key stakeholders, bring in additional resources to the welfare sector (and potentially to other sectors) and encourage community participation and openness that has potential to lead to a 
higher level of public value and increases the availability of services to those who need them most.

The third research question looked at factors influencing the development and implementation of cocreated peer-to-peer economy based public services. Based on the cases of Helpific and Caremate, it appeared that being given a creative environment (hackathons) to trial and launch new solutions was of critical importance. Additionally, support appears to be available for new and innovative services in the social welfare sector in the Estonian context. For example, in 2018 grants totalling five million euros have been made available. This support was not yet available when Helpific and Caremate were initiated, however it can be used to develop the solution further. Although there has been assistance at a ministerial level, the bottle-neck appears to be at the local municipal level. Assuring that local municipalities would be included in these development processes more, such as government sponsored hackathons, may allow solutions to gain more acceptance at the local municipal level. When looking at what could be done additionally to support such solutions, mention was made that central government could take on a bigger role in promoting good examples and raising overall awareness. As one of the interviewees said, "Local municipalities can become very used to doing things the way they have always done and they might need a little nudge or a gentle push in a new direction." Mention was also made that innovation needs to become a more natural part of day-to-day processes, and that this is something which does not happen overnight. Interviewees also talked about the need to create a pool of new ideas and solutions support is needed to develop new ideas into prototypes and to develop prototypes into working solutions. Communities must be empowered for this. It seems that this support is increasingly available in the system, but there is still a long way to go.

Based on these two cases, three initial propositions are put forward:

1) Whilst most public organisations cannot be changed easily, and basic routines tend to remain unaltered, new solutions are more likely to emerge when the organisation allows room and a supportive environment for solutions to be cocreated;

2) In order for co-created peer-to-peer solutions to be integrated into routines in the public sector and for these solutions to gain acceptance among decisionmakers, stakeholders that know the system and have the ability to facilitate actual changes in the system (e.g. through funding) must be included in the co-creation process;

3) The specifics of the sector must be considered, for example barriers such as lack of awareness and technological know-how may be solved by using contact points already working within the system to disseminate awareness of the new services.

\section{Conclusion}

Innovative solutions like Helpific and Caremate appear to hold substantial potential for changing the current system of public service delivery. This article examined the development of two co-created peer-to-peer platforms, Helpific and Caremate, and the barriers and enablers these solutions encountered. From these, we learn of the need for room and for support, for experience of use in the field and for overcoming the digital divide. Based on these cases we argue that once these required prerequisites have been established, cocreated peer-to-peer economy based platforms can hold substantial potential to changing government welfare and introducing new ways of delivering public services. Whilst public money has not yet been directed to these platforms to finance service delivery, there are currently active discussions underway on this matter in Estonia. Co-created peer-to-peer solutions can bring in additional resources into the public sector, encourage community participation and openness which lead to a higher level of added public value and better availability of the services. However, several aspects still require further research, such as gaining a better understanding of what the expectations of both service users and local municipalities currently organizing 'traditional' services are; and how to overcome the barriers currently in place. Also, this approach to public service delivery is not a one-size-fits-all solution and issues such as trust, accountability, security, public financing and legality must be examined further. Other underlying question that still requires further research is whether co-creation is always feasible and do solutions like co-created peerto-peer platforms actually manage to create greater added value for the end user and other stakeholders, such as local municipalities.

Acknowledgements. This work is supported by Doctoral School in Economics and Innovation, ASTRA project TTÜ's development plan for 2014-2022 code 2014-2020.4.01.160032 (European Union, European Regional Development Fund), the European Commission (OpenGovIntelligence H2020 grant 693849), and TTÜ Digital Governance Competency Center (SS483).

\section{References}

[1] McBride, K., Aavik, G., Kalvet, T. and R. Krimmer. "Cocreating an Open Government Data Driven Public Service: The Case of Chicago's Food Inspection Forecasting Model", Proceedings of the 51st Hawaii International Conference on System Sciences (HICSS), 2018, IEEE, pp. 2453-2462. 
[2] Mager, B., 2016, "Service Design Impact Report: Public Sector." $\quad$ From: https://www.service-designnetwork.org/uploads/sdn-impact-report_public-sector.pdf, accessed 2018-05-01.

[3] Simmons, R. and B. Johnston, "A Joined-up Approach to User Participation in Public Services: Strengthening the 'Participation Chain'", Social Policy \& Administration, 39(3), 2005, pp. 260-283.

[4] Janssen, M., Charalabidis, Y., and A. Zuiderwijk, "Benefits, Adoption Barriers and Myths of Open Data and Open Government", Information Systems Management, 29(4), 2012, pp. 258-268.

[5] Bertot, J. C., Jaeger, P. T., Munson, S. and T. Glaisyer, "Engaging the Public in Open Government: Social Media Technology and Policy for Government Transparency", Computer, 43(11), 2010, pp. 53-59.

[6] Osborne, S. P., "Delivering Public Services: Time for a new theory?", PMR, 12(1), 2010, pp. 1-10.

[7] Fledderus, J., Brandsen, T. and M. Honigh, "Restoring Trust Through the Co-Production of Public Services: A theoretical elaboration", Public Management Review, 16(3), 2014, pp. 424-443.

[8] Brandsen, T., and M. Honingh, "Distinguishing Different Types of Coproduction: A Conceptual Analysis Based on the Classical Definitions", Public Administration Review, 73(3), 2015, pp. 427-435.

[9] Linders, D., "From e-government to we-government: Defining a typology for citizen coproduction in the age of social media", GIQ 29, 2012, pp. 446-454.

[10] Osborne, S.P., and K. Strokosch, "It takes Two to Tango? Understanding the Co-production of Public Services by Integrating the Services Management and Public Administration Perspectives", British Journal of Management, 24, 2013, pp. 31-47.

[11] Pestoff, V., Osborne S. P. and T. Brandsen, "'Patterns of co-production in public services", Public Management Review, 8, 2006, pp. 591-595.

[12] Needham, C. and S. Carr, Co-Production: An Emerging Evidence Base for Adult Social Care Transformation, London: Social Care Institute for Excellence, 2009.

[13] Stockdale, R., and C. Standing, "An Interpretive Approach to Evaluating Information Systems: A Content, Context, Process framework", European Journal of Operational Research, 173, 2006, pp. 1090-1102.

[14] Schmidt, V. A., "Discursive Institutionalism: The Explanatory Power of Ideas and Discourse", Annual Review of Political Science, 11(1), 2008, pp. 303-326.

[15] Kala, K., "The Social Origins of The Estonian Non-Profit Sector", Trames, 12(4), 2008, pp.441-449.

[16] Devos, G., Buelens, M., and D. Bouckenooghe, "Contribution of Content, Context, and Process to Understanding Openness to Organisational Change: Two Experimental Simulation Studies", Journal of Social Psychology, 147(6), 2007, pp. 607-630.

[17] Heeks, R., "E-Government as a Carrier of Context", Journal of Public Policy, 25(1), 2005, pp. 51-74.

[18] Self D., Armenakis, A., and M. Schraeder, "Organisational Change Content, Process, and Context: A Simultaneous Analysis of Employee Reactions", Journal of Change Management, 7, 2007, pp. 211-229.
[19] Ongaro, E., "Explaining Contextual Influences on the Dynamics of Public Management Reforms: Reflections on Some Ways Forward", in: Retirement Workshop for Professor Christopher Pollitt, 29 - 30 March 2012, ed Catholic University of Leuven (K.U. Leuven), 2012.

[20] European Commission, 2013, "A Vision for Public Services." From: https://ec.europa.eu/digital-singlemarket/en/news/vision-public-services, accessed 2018-04-16. [21] Mahoney, J. and G. Goertz, "A Tale of Two Cultures: Contrasting Quantitative and Qualitative Research", Political Analysis, 14, pp. 227-249, 2006.

[22] Eisenhardt, K. M., "Building Theories from Case Study Research", AoM Review, 14(4), 1989, pp. 532-550.

[23] Flyvbjerg, B., "Five Misunderstandings About CaseStudy Research", Qualitative Inquiry, 12(2), 2006, 219-245.

[24] Riigikogu, 2015, "Social Welfare Act." From: https://www.riigiteataja.ee/en/eli/ee/517012017002/consolide /current, accessed 2018-06-01.

[25] World Bank, 2017, "Reducing the Burden of Care in Estonia."

From:

https://riigikantselei.ee/sites/default/files/content-

editors/Failid/hoolduskoormus/estonia_ltc_report_final.pdf, accessed 2018-05-17.

[26] Estonian Chamber of Disabled People, 2018, "The Shadow Report on fulfilling the Convention on the Rights of Persons with Disabilities in Estonia." From: https://www.epikoda.ee/wp-content/uploads/2018/03/

EPIK_variraport_webi.pdf, accessed 2018-06-05.

[27] E-Estonia, "Estonia ranks third in Europe regarding the highest number of startups per capita." From: https://eestonia.com/estonia-is-ranked-the-third-in-europe-regardingthe-highest-number-of-startups-per-capita/, accessed 2018$05-15$.

[28] Aavik G., and R. Krimmer, "Integrating Digital Migrants: Solutions for Cross-Border Identification from E-Residency to eIDAS. A Case Study from Estonia", in: Scholl H. et al. (eds) Electronic Government. EGOVIS 2016. Lecture Notes in Computer Science, 9820.

[29] Kozik, J., 2017, "Regulating Uber in the Light of the Emerging Sharing Economy." From: https://digi.lib.ttu.ee/i/file.php?DLID=8410\&t=1, accessed 2018-05-09.

[30] Lember, V., Kattel, R., and P. Tõnurist, "Technological capacity in the public sector: the case of Estonia", International Review of Administrative Sciences 84(2), 2016, pp. 214-230.

[31] Kersti Kaljulaid, 2016, Official transcript of the speech given at the Higher Courses on Social Protection. From: https://www.president.ee/et/ametitegevus/koned/12632-201610-27-10-33-35/index.html, accessed 2018-05-22.

[32] The Expert Group on Self-Driving Vehicles created under the Government Office, 2018, The Beginning of the Age of Self-Driving Vehicles. From: https://riigikantselei.ee/sites/default/files/riigikantselei/stratee giaburoo/isejuhtivad_loppraport.pdf, accessed 2018-05-10. [33] Ministry of Social Affairs, 2016, "Welfare Development Plan." From: https://www.sm.ee/sites/default/files/contenteditors/eesmargid_ja_tegevused/welfare_development_plan_ 2016-2023.pdf ,accessed 2018-05-12. 